\title{
The psychopathological scenario in asthma
}

Dear Editor,

According to recently published data in Portugal, respiratory diseases are the $5^{\text {th }}$ leading cause of hospitalization, the $1^{\text {st }}$ leading cause of intra-hospital mortality, and the $3^{\text {rd }}$ leading cause of mortality (preceded by cardiovascular and oncological diseases) ${ }^{1}$.

Asthma is a respiratory disease characterized by chronic and heterogeneous airway inflammation, defined by a constellation of respiratory symptoms such as wheezing, dyspnea, chest tightness, and coughing. The symptoms are diverse in their frequency and intensity and are associated with a variable limitation of expiratory flow ${ }^{2}$. The prevalence of asthma is high, particularly in pediatric and young adult patients.

As a potentially disabling chronic disease with high expression at a young age, the importance of early intervention is highlighted to guarantee symptomatic control. This involves a complex process of adaptation and implies adherence to a therapeutic plan that includes pharmacological and non-pharmacological measures.

The diagnosis of a chronic disease leads to a set of changes in social, professional and personal roles, which increases the vulnerability to psychopathology. The psychological component influences the respiratory condition, namely: i) the onset of asthmatic crises; ii) the persistence/worsening of symptoms during the crises; and iii) resistance to pharmacotherapy. The presence of anxious and depressive symptoms can negatively influence the clinical outcome, contributing to: i) worse quality of life, ii) less adherence to drug therapy; iii) greater severity of symptoms; iv) greater functional deficit; v) increased frequency and therapeutic dosage; vi) greater use of health services; and vii) reduction of average life expectancy.

In reverse, asthma as a chronic and disabling disease can be a triggering factor for anxiety and/or depressive disorders.

There are some immunological pathways that explain the relationship between these disorders. Chronic elevation of cortisol in stressful situations leads to greater resistance to the anti-inflammatory effects of glucocorticoids ${ }^{3}$. There is a specific increase in the cytokines IL-1 $\beta$ and IL- 6 , which are related to neurodegeneration ${ }^{4}$. This is a risk factor for systemic and/or airway inflammation in asthma ${ }^{5}$. Another cytokine involved in inflammatory responses, such as alpha interferon (IFN- $\alpha$ ), can contribute to glucocorticoid resistance by decreasing the function of glucocorticoid receptors. It leads to fatigue in individuals with depression ${ }^{6}$.

Additionally, a depressive mood is related to an increase in the fraction of exhaled nitric oxide (FeNO)

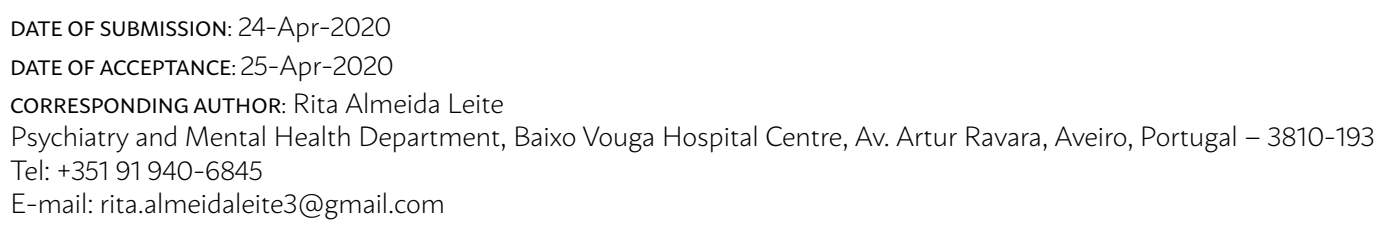


in asthma ${ }^{7}$. On the other hand, excess glucocorticoids in asthma can also activate immune pathways, which increase the vulnerability to psychopathology ${ }^{6}$.

The rate of adherence to treatment for patients with asthma is relatively low, occurring in just about $30 \%$ of cases $^{8}$. Asthma treatment guidelines such as GINA or the latest revision of the Clinical Guidance Standard of the General Directorate of Health on monitoring and treatment for asthma control, recommend building a good doctor-patient relationship, which improves adherence and prognosis.

Thus, there is a close correlation between psychiatric comorbidity and worse clinical outcomes in asthma, and a better understanding of this association may have a significant clinical impact. There is a need for an integrated care response, with medical and psychiatric guidance combined in a multidisciplinary approach, with effective clinical communication of an individualized plan and a consequent potential reduction in hospital costs.

\section{REFERENCES}

1. Portugal. Ministério da Saúde. Direção-Geral da Saúde. Programa nacional para as doenças respiratórias 2017. Lisboa: Direção-Geral da Saúde; 2017. [cited 2020 Mar 15]. Available from: https://www. dgs.pt/portal-da-estatistica-da-saude/diretorio-de-informacao/ diretorio-de-informacao/por-serie-880758-pdf.aspx?v=\%3d\%3dDwAAAB\%2bLCAAAAAAABAArySzltzVUy81MsTU1MDAFAHzFEfkPAAAA

2. Global Initiative for Asthma. Global strategy for asthma management and prevention 2019. [cited 2020 Mar 15]. Available from: www.ginasthma.org/ gina-reports/

3. Trueba AF, Simon E, Auchus RJ, Ritz T. Cortisol response to acute stress in asthma: moderation by depressive mood. Physiol Behav. 2016;159:20-6.

4. Carlson SM, Kim J, Khan DA, King K, Lucarelli RT, McColl R, et al. Hippocampal volume in patients with asthma: results from the Dallas Heart Study. J Asthma. 2017;54(1):9-16.

5. Wu MK, Wang HY, Chen YW, Lin PY, Wu CK, Tseng PT. Significantly higher prevalence rate of asthma and bipolar disorder co-morbidity: a meta-analysis and review under PRISMA guidelines. Medicine. 2016;95(13):e3217.

6. Bulcun E, Turkel Y, Oguztürk O, Dag E, Buturak SV, Ekici A, et al. Psychological characteristics of patients with asthma. Clin Respir J. 2018;12(1):113-8.

7. Van den Bemt L, Luijks H, Bor H, Termeer E, Lucassen P, Schermer T. Are asthma patients at increased risk of clinical depression? A longitudinal cohort study. J Asthma. 2016;53(1):43-9.

8. World Health Organization. Adherence to long-term therapies: evidence for action. Geneva: World Health Organization; 2003. [cited 2020 Mar 15]. Available from: https://apps.who.int/iris/bitstream/handle/10665/42682/9241545992.pdf 